\title{
Gas Permeation through Oxide Scale Formed at Low Oxygen Potentials
}

\author{
Yuji Ikeda, ${ }^{*}$ Kazuyoshi Nii* and Fumio Hirose* \\ * National Research Institute for Metals
}

\begin{abstract}
The severe carburization and decarburization at lower oxygen potentials and internal sulfidation in $\mathrm{SO}_{2}$ suggest strongly the presence of physical defects, such as micropores and fissures, allowing the passage of gaseous species in the scale, because the solid state diffusion rate of carbon and sulfur in oxide is very low. In the present work sulfur decoration method was applied to detect such defects. Fe-Cr alloys were oxidized at $1173 \mathrm{~K}$ in impure $\mathrm{Ar}, \mathrm{H}_{2}-\mathrm{H}_{2} \mathrm{O}$ or $\mathrm{O}_{2}$. At the end of oxidation run they were sulfidized in $\mathrm{H}_{2} \mathrm{~S}$ for about $60 \mathrm{~s}$ at the same temperature. Presence of physical defects in the scale at low oxygen potential was clearly shown by penetration of sulfur into the scale. Such defects allow oxidant gas penetration to the scale/alloy interface and consequently accelerate the oxidation rate, especially the oxidation of $\mathrm{Fe}-10 \mathrm{Cr}$ and $-15 \mathrm{Cr}$ alloys in Ar.
\end{abstract}

\section{Introduction}

In atmospheres with low oxygen potentials, such as $\mathrm{He}$ atmosphere in High Temperature Gascooled Reactor, carburization or decarburization of materials, which deteriorates mechanical properties of the materials ${ }^{1)}$, takes place depending on a carbon potential even though an oxide scale covers the alloy surface ${ }^{2), 3)}$. It is, therefore, considered that an oxide scale formed in atmospheres with low oxygen potentials is not sufficiently compact to prevent $\mathrm{CO}$ and $\mathrm{CO}_{2}$ gas permeation. In fact when some steels were oxidized firstly in normal $\mathrm{CO}_{2}$ and subsequently in $\mathrm{CO}_{2}$ containing $\mathrm{CO}_{2}{ }^{18}$ or $\mathrm{C}^{14} \mathrm{O}_{2}, \mathrm{O}^{18}$ was detected in the inner oxide layer adjacent to the metal substrate and $\mathrm{C}^{14}$ in the near interfacial region between the metal and the oxide ${ }^{4)} \sim 7$. . In addition, when $\mathrm{Co}$, after covered with an apparently compact and adherent scale by oxidation in impure Ar, was exposed to Ar- $2 \% \mathrm{SO}_{2}$, sulfide was observed at the oxide scale/metal interface ${ }^{8)}$. On the $\mathrm{Ni}-25 \mathrm{Cr}$ and $\mathrm{Co}-25 \mathrm{Cr}$ alloys also were produced sulfide nodules by exposure to $\mathrm{H}_{2}-\mathrm{H}_{2} \mathrm{O}-\mathrm{H}_{2} \mathrm{~S}$ atmosphere after pre-oxidation in $\mathrm{H}_{2}-\mathrm{H}_{2} \mathrm{O}$ atmosphere ${ }^{9)}$. These results suggest very strongly that an oxide scale formed in atmospheres with low oxygen potentials, such as $\mathrm{CO}_{2}$, impure $\mathrm{Ar}$ and $\mathrm{H}_{2}-\mathrm{H}_{2} \mathrm{O}$, contains

* 2-3-12, Nakameguro, Meguroku, Tokyo, 153 Japan physical defects such as pores or fissures through which gaseous species can pass inward or outward.

The object of this work is to investigate the oxidation behavior of $\mathrm{Fe}-\mathrm{Cr}$ alloys in atmospheres with low oxygen potentials and to confirm that physical defects can be produced at low oxygen potentials more extensively than at high oxygen potentials by using sulfur decoration method ${ }^{10), 11}$.

\section{Experimental}

\subsection{Specimen Preparation}

Electrolytic $\mathrm{Fe}$ and $\mathrm{Cr}$ were weighed and arcmelted. The alloys were hot- and cold-rolled, annealed in a stream of $\mathrm{Ar}-1 \% \mathrm{H}_{2}$ at $1,373 \mathrm{~K}$ for $7.2 \mathrm{ks}$ and cut into coupons about $10 \times 10 \times 1 \mathrm{~mm}$. Their compositions are given in Table 1. The c supons were polished through $3 / 0$ grit emery paper, washed with alcohol and distilled water, and dried rapidly.

\subsection{Oxidation}

Specimens, drilled, weighed and hung with a quartz bar on a boat, were inserted into a furnace heated at $1,173 \mathrm{~K}$ and oxidized for $90 \sim 720 \mathrm{ks}$ in a stream of Ar (residual oxygen partial pressure $\left.p_{\mathrm{O}_{2}} \sim 10 \mathrm{~Pa}\right), \mathrm{H}_{2}-\mathrm{H}_{2} \mathrm{O}\left(p_{\mathrm{O}_{2}} \sim 2 \times 10^{-17} \mathrm{~Pa}\right)$ and $\mathrm{O}_{2}$ under atmospheric pressure. The flow rate was about $3 \mathrm{~cm}^{3} / \mathrm{s}$ for $\mathrm{Ar}$ and $\mathrm{O}_{2}$, and $17 \mathrm{~cm}^{3} / \mathrm{s}(=1 \mathrm{l} /$ min) for $\mathrm{H}_{2}-\mathrm{H}_{2} \mathrm{O}$. 
Table 1 Chemical composition of $\mathrm{Fe}-\mathrm{Cr}$ alloys (mass \%).

\begin{tabular}{cccccccc}
\hline Alloy & Cr & C & Si & Ni & S & Al & Fe \\
\hline Fe-10Cr & 9.50 & 0.003 & 0.003 & 0.004 & 0.010 & 0.005 & Bal. \\
Fe-15Cr & 14.65 & 0.004 & 0.002 & 0.005 & 0.011 & 0.003 & Bal. \\
Fe-20Cr & 19.20 & 0.005 & 0.003 & 0.005 & 0.010 & 0.003 & Bal. \\
Fe-30Cr & 29.0 & 0.005 & 0.003 & 0.005 & 0.013 & 0.003 & Bal. \\
\hline
\end{tabular}

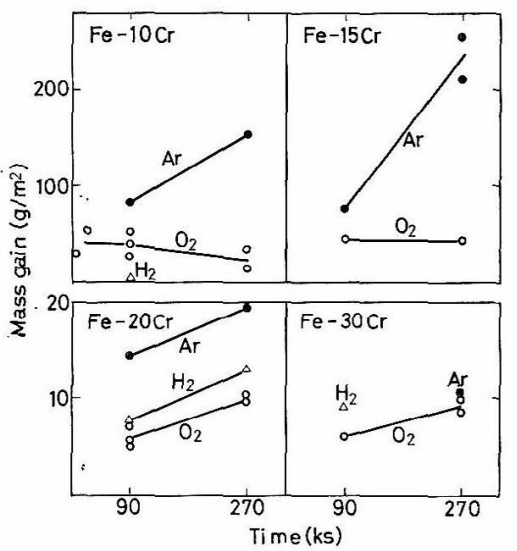

Fig. 1 Mass gain of $\mathrm{Fe}-\mathrm{Cr}$ alloys oxidized at $1,173 \mathrm{~K}$.

$\mathrm{O}:$ in $\mathrm{O}_{2}$

-: in $\mathrm{Ar}\left(p_{\mathrm{O}_{2}} \sim 10 \mathrm{~Pa}\right)$

$\triangle$ : in $\mathrm{H}_{2}-\mathrm{H}_{2} \mathrm{O}\left(p_{\mathrm{O}_{2}} \sim 2 \times 10^{-17} \mathrm{~Pa}\right)$

\subsection{Sulfur Decoration}

At the end of oxidation run, the oxidant gas was replaced by Ar without removing the specimens in the furnace. Then $\mathrm{H}_{2} \mathrm{~S}$ gas was passed through the reaction tube for $30 \sim 60 \mathrm{~s}$. If there are physical defects, such as pores or fissures, in the oxide scale, $\mathrm{H}_{2} \mathrm{~S}$ gas will penetrate through the defects into the scale/metal interface and sulfides will be formed along the defects and at the metal surface.

The specimens were then mounted in resin and the sulfur distribution was examined by EPMA on a polished section.

\section{Results}

\subsection{Mass Gain}

Mass gains of $\mathrm{Fe}-\mathrm{Cr}$ alloys oxidized at $1,173 \mathrm{~K}$ in various atmospheres are shown in Fig. 1. The mass gain was large in Ar, especially for lower $\mathrm{Cr}$ alloys. This suggests that the scale formed in $\mathrm{Ar}$ is not compact and not adherent to the alloy substrate. The mass gain in $\mathrm{O}_{2}$ is smaller than those in other gases. The mass gain of $\mathrm{Fe}-10 \mathrm{Cr}$ alloy was very small in $\mathrm{H}_{2}-\mathrm{H}_{2} \mathrm{O}$. This is because only $\mathrm{Cr}$ can be oxidized in this atmosphere and

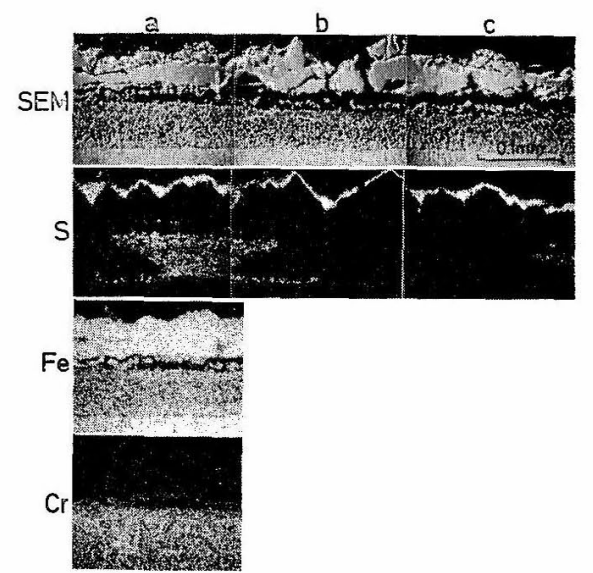

Fig. $2 \mathrm{Fe}-10 \mathrm{Cr}$ oxidized in $\mathrm{Ar}\left(p_{\mathrm{O}_{2}} \sim 10 \mathrm{~Pa}\right)$ at $1,173 \mathrm{~K}$ for $270 \mathrm{ks}$.

the rate of Cr supply from the bulk to the surface is very low in this alloy. The slow rate of $\mathrm{Cr}$ supply is attributed to the low concentration of $\mathrm{Cr}$ and the slow diffusion rate of $\mathrm{Cr}$ in this alloy which has the fcc structure at $1,173 \mathrm{~K}$.

\subsection{Sulfur Decoration Results}

Figure 2 represents the EPMA results on the $\mathrm{Fe}-10 \mathrm{Cr}$ alloy oxidized at $1,173 \mathrm{~K}$ in a stream of Ar. The considerable penetration of sulfur is observed in the inner layer and along the scale/ alloy interface. This means that the oxidant gas penetrated deep into the scale/alloy interface during the oxidation. The large mass gain of the $\mathrm{Fe}-10 \mathrm{Cr}$ alloy in $\mathrm{Ar}$ is reasonably attributed to this extensive gas penetration and to the resulting absence of $\mathrm{Cr}$ rich protective oxide layer. In $\mathrm{O}_{2}$, on the other hand, the gas penetration was more moderate and a $\mathrm{Cr}$ rich layer was formed (Fig. 3).

Figures 4 and 5 represent the results on higher $\mathrm{Cr}$ alloys. Because the SEM images in these figures do not show ballooning of the scale, compressive growth stress and resultant scale cracking are considered to be of a slight extent at low oxygen potential. However, the $\mathrm{S}$ images show local gas penetration through the scale and therefore the 


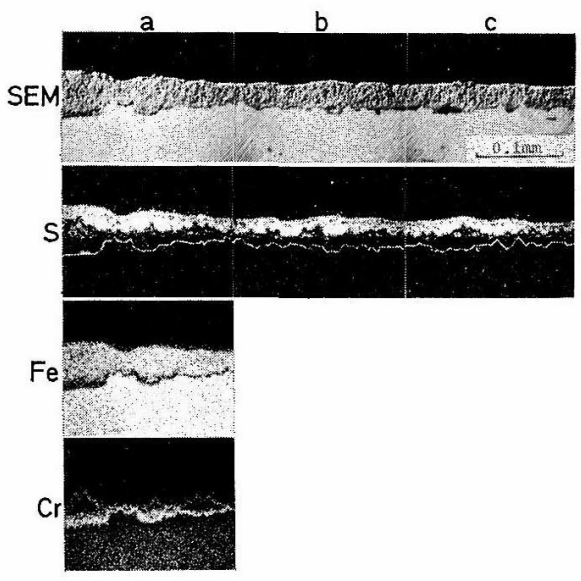

Fig. $3 \mathrm{Fe}-10 \mathrm{Cr}$ oxidized in $\mathrm{O}_{2}\left(10^{5} \mathrm{~Pa}\right)$ at $1,173 \mathrm{~K}$ for $270 \mathrm{ks}$. The location of the scale/alloy interface is sketched in photos of $\mathrm{S}$ as a fine white line.

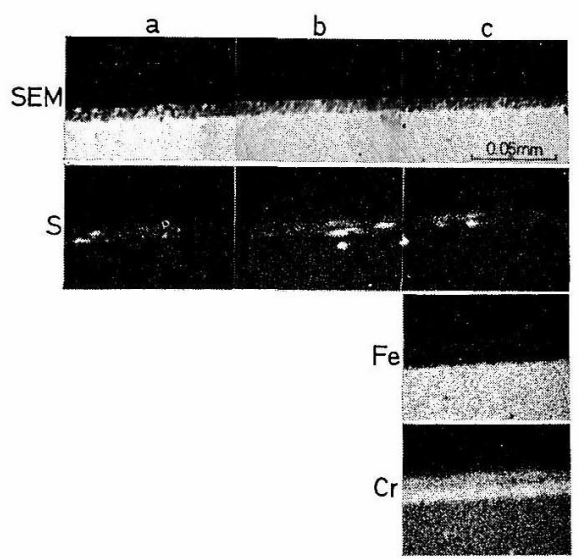

Fig. $4 \mathrm{Fc}-20 \mathrm{Cr}$ oxidized in $\mathrm{H}_{2}-\mathrm{H}_{2} \mathrm{O}\left(p_{\mathrm{O}_{2}} \sim 2 \times 10^{-17}\right.$ $\mathrm{Pa})$ at $1,173 \mathrm{~K}$ for $270 \mathrm{ks}$. Sulfur appears to be distributed in two layers. But the upper layer is the uppermost part of the scale which was detached together with resin from the specimen. One round point on photo $b$ and an another point between photos $b$ and c correspond to penetration.

existence of physical defects in it. Namely, the scale formed at low oxygen potential is not sufficiently protective though cracks are not generated by compressive growth stress. In Figs. 4 and 5, $\mathrm{S}$ and $\mathrm{Cr}$ are distributed in two layers. This is attributed to the contraction of resin during solidification. This contraction generated very often a crack between the resin and the specimen. When a crack was generated, an uppermost part of the scale sticked firmly in the resin was detached from

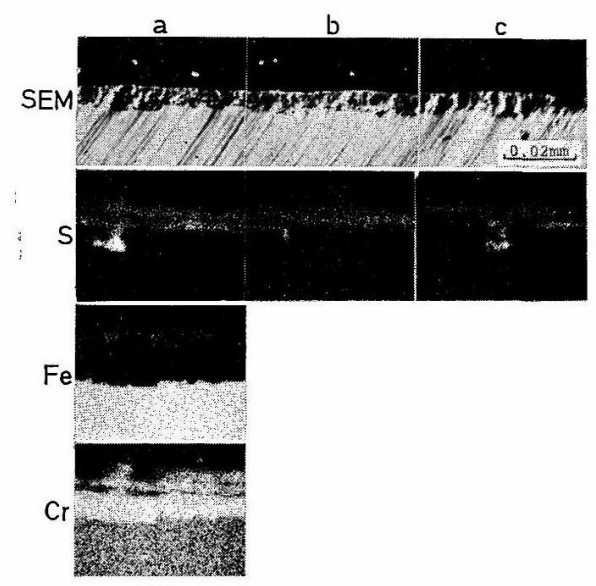

Fig. $5 \mathrm{Fe}-30 \mathrm{Cr}$ oxidized in $\mathrm{Ar}\left(p_{\mathrm{O}_{2}} \sim 10 \mathrm{~Pa}\right)$ at $1,173 \mathrm{~K}$ for $270 \mathrm{ks}$. The uppermost part of the scale was detached from the specimen, as seen in Fig. 4.

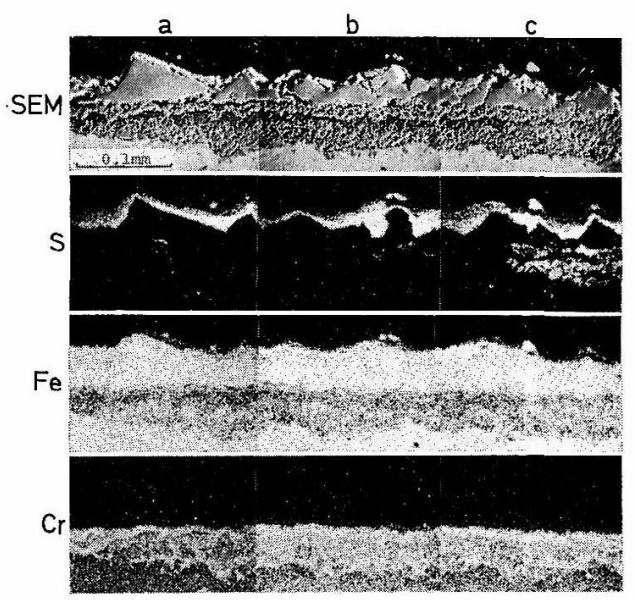

Fig. $6 \mathrm{Fe}-15 \mathrm{Cr}$ oxidized in $\mathrm{Ar}\left(p_{\mathrm{O}_{2}} \sim 10 \mathrm{~Pa}\right)$ at $1,173 \mathrm{~K}$ for $90 \mathrm{ks}$.

the specimen. This detached part corresponds to the upper layer in $\mathrm{S}$ and $\mathrm{Cr}$ images in Figs. 4 and 5. Only two round points on photos $b$ and $c$ correspond to the penetration.

As reported previously, the crack in the scale was not always observed through the oxidation run in $\mathrm{O}_{2}$, because the crack, though produced repeatedly during oxidation, is relatively easily healed in $\mathrm{O}_{2}$. Thus it was expected for the oxidation in $\mathrm{Ar}$ and also in $\mathrm{H}_{2}-\mathrm{H}_{2} \mathrm{O}$ that the healing of physical defects took place, and that the gas penetration occurred intermittently but not continuously. Figures 6 and 7 represent the results of oxidation for $90 \mathrm{ks}$, and Figure 8 for $720 \mathrm{ks}$. Contrary to the expectation, the gas penetration 


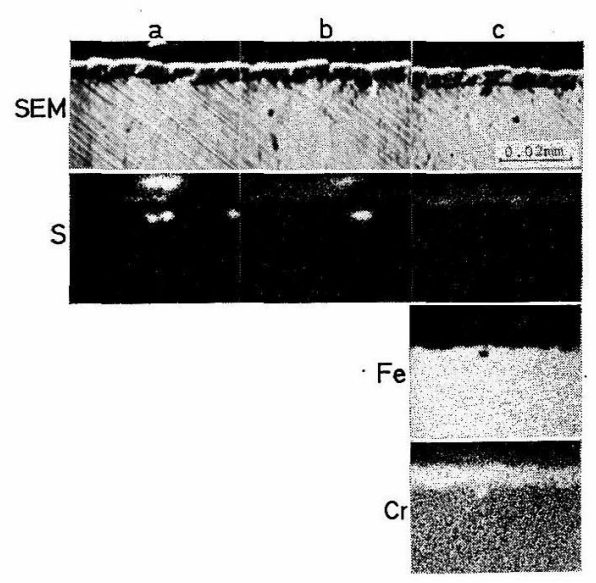

Fig. $7 \mathrm{Fe}-20 \mathrm{Cr}$ oxidized in $\mathrm{Ar}\left(p_{\mathrm{O}_{2}} \sim 10 \mathrm{~Pa}\right)$ at $1,173 \mathrm{~K}$ for $90 \mathrm{ks}$. The uppermost part of the scale was detached from the specimen, as seen in Fig. 4.

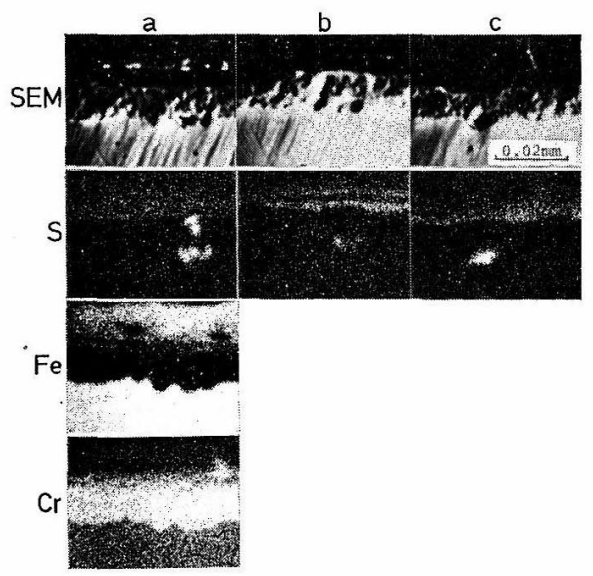

Fig. 8. $\mathrm{Fe}-20 \mathrm{Cr}$ oxidized in $\mathrm{Ar}\left(p_{\mathrm{O}_{2}} \sim 10 \mathrm{~Pa}\right)$ at $1,173 \mathrm{~K}$ for $720 \mathrm{ks}$. The uppermost part of the scale was detached from the specimen, as seen in Fig. 4.

is always obscrved irrespective of oxidation time, so the scale formed at low oxygen potential is considered to contain always physical defects.

\section{Discussion}

As shown in Figs. 2, 4, 5, 6, 7 and 8, physical defects allowing gas penetration exist always in the scale formed at low oxygen potentials. Since the sulfidation time is about $60 \mathrm{~s}$, the observed sulfur penetration is exclusively attributed to gaseous diffusion but not to solid state diffusion. Especially the gas penetration took place very largely in the inner layer of the scale formed on $\mathrm{Fe}-10 \mathrm{Cr}$ and $\mathrm{Fe}-15 \mathrm{Cr}$ alloys in Ar (Figs. 2, 6).
This result shows that these inner layers were very porous. Such gas penetration not only causes inward growth of the scale but also accelerates outward growth of outer layer by preventing the formation of a $\mathrm{Cr}$ rich protective layer, and resulting naturally in large mass gain of these alloys in Ar (Fig. 1). For higher $\mathrm{Cr}$ alloys also the gas penetration must accelerate the oxidation rate.

On the other hand, in $\mathrm{O}_{2}$ scale cracks are sometimes generated to allow gas penetration but they are more ready to be healed than the physical defects formed at low oxygen potentials. In $\mathbf{O}_{z}$ even 5 - and $10 \% \mathrm{Cr}$ alloys are able to form a moderately protective oxide layer enriched in $\mathrm{Cr}$.

Although following mechanisms may be cited for the cause of physical defect generation, any of them is not conclusive.

1) Mechanical cracking of scale

Scale cracking due to growth stress is usually an important factor for oxidation resistance. But in this work scale spalling and ballooning were much less extensive than in $\mathrm{O}_{2}$, namely the growth stress was low. Therefore, the scale formed in $\mathrm{Ar}$ and $\mathrm{H}_{2}-\mathrm{H}_{2} \mathrm{O}$ is considered to crack less readily than that in $\mathrm{O}_{2}$.

2) Microchannels remaining at the grain boundary of scale ${ }^{12)}$

Microchannels may remain at grain boundaries of growing oxide and serve as a gas penetration path. If it were the case, gas penetration should take place at particular points, where scale morphology and thickness would differ from those at other part. In practice, however, the scale morphology and thickness were similar throughout the scalc, when oxidized in $\mathrm{Ar}$ and $\mathrm{H}_{2}-\mathrm{H}_{2} \mathrm{O}$.

3) Dissociation fissure ${ }^{13), 14)}$

If dissociation fissures were repeatedly opened and closed over the whole scale, gas penetration would be always detected and the scale would have a similar morphology and thickness all over a same specimen. However, it is doubtful that the surface oxide is reduced at the tip of dissociation fissure even in Ar with an oxygen potential of $10 \mathrm{~Pa}$.

Thus conclusive remarks can not be made upon the causes of physical defect generation, but in any way the scale formed at low oxygen potential inherently contains physical defects through which gaseous species can pass.

The characteristics of the oxide scale are summarized as follows:

1) At high oxygen potential the scale is cracked by growth stress but healed readily. 
2) At low oxygen potential the scale is not cracked but inherently porous and healed very hardly.

(Received September 4, 1985)

\section{References}

1) Y. Hosoi and A. Abe: Met. Trans., 6A, 1171 (1975).

2) T. Hirano, M. Okada, H. Araki, T. Noda, H. Yoshida and R. Watanabe: Met. Trans., 11A, 1883 (1980).

3) T. Hirano, H. Araki and H. Yoshida: J. Nucl. Mat., 97, 272 (1981).

4) A. M. Pritchard, J. E. Antill, K. R. J. Cottell, K. A. Peakall and A. E. Truswell: Oxid. Met., 9, 181 (1975).

5) D. G. Lees and J. M. Calvert: Corros. Sci., 16, 767 (1976).

6) A.M. Pritchard, N.E.W. Hartley, J.F. Singleton and A. E. Truswell: Corros. Sci., 20, 1 (1980).
7) M. R. Taylor, J. M. Calvert, D. G. Lees and D. B. Meadowcroft: Oxid. Met., 14, 499 (1980).

8) P. Singh and N. Birks: Oxid. Met., 12, 23 (1978).

9) H. Hindam and D. P. Whittle: Corros., 38, 32 (1982).

10) Y. Ikeda and K. Nii: Oxid. Met., 12, 487 (1978).

11) Y. Ikeda and K. Nii: Trans. Nat. Res. Inst. Met., 26, 52 (1984).

12) W. E. Boggs and R. H. Kachik: J. electrochem. Soc., 116, 424 (1969).

13) S. Mrowec and T. Werber: "Gas Corrosion of Metals", p. 101, the Foreign Scientific Publications Department of the National Center for Scientific, Technical and Economic Information, Warsaw, Poland (1978).

14) G. B. Gibbs and R. Hales: Corros. Sci., 17, 487 (1977). 